\title{
The Determination of Preventive Maintenance using Simulated Annealing Algorithm based on Weighted Fitness Function
}

\author{
Yeny Krista Franty *, Budhi Handoko \\ Statistics Department, Padjadjaran University, Indonesia \\ Jl. Bandung - Sumedang km 21 Sumedang Jawa Barat, Indonesia \\ * Corresponding author: yeny.krista@unpad.ac.id
}

\section{ARTICLE INFO}

Article history

Received August 7, 2018

Revised November 5, 2018

Accepted November 30, 2018

Available Online February 28, 2019

Keywords

Simulated annealing

Preventive maintenance

Weibull distribution

Failure

\begin{abstract}
This study aims to determine the machine maintenance schedule. We use the Simulated Annealing Algorithm. Fitness and reliability functions are functions that are used in the optimization process. Several weighting scenarios are done to see the unity of the function. The results of the scenario produce several alternative schedules. This algorithm is implemented on machines that have more than one sub-machine. This submachine is a smaller engine system part. This sub-machine also has one particular function. The results of the study show that the optimal engine maintenance period to use is six periods. There are five scheduling scenarios used in this problem. The resulting schedule can increase the value of reliability and can minimize costs.
\end{abstract}

This is an open-access article under the CC-BY-SA license.

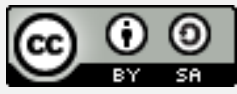

\section{Introduction}

Maintenance is an important activity in the manufacturing industry. Preventive maintenance can increase the life of the engine and prevent breakdown. The machine has a breakdown when production and might severe fatal impacts. These impacts include disrupted production processes, lost production, more extended downtime, and expensive repair costs. Regarding the importance of machine maintenance, companies require a maintenance period. However, generally, the maintenance period is only based on the machine book manual. If the machine operates relatively long, the machine experiences an unexpected breakdown. Therefore, the authors propose preventive maintenance based on actual machine breakdown. Hence, the maintenance period does not depend on the manual machine book. Preventive maintenance based on breakdown time data can use the classical approach. Some of these approaches are the age replacement model and block replacement model. The method is used for one sub-machine and provides information on treatment time on the timing of sub-machine replacement. Pan, et al. [1] reviewed preventive maintenance for a single machine. They proposed a single machine scheduling model. The model aims to minimize the average scheduling time. Another approach for determining the maintenance schedule is by using a genetic algorithm. This approach was 
applied by Chen, et al. [2]. They used Genetic Algorithms (GA) to schedule preventive maintenance of rocket machines. Ayoobian and Mohsendokht [3] proposed genetic algorithms to schedule maintenance of nuclear power plants. Moinian, et al. [4] developed a genetic algorithm for scheduling maintenance of gas turbine preventive maintenance.

Another type of metaheuristic method is the Simulated Annealing algorithm (SA). SA is a method for solving combinatorial optimization problems. SA discusses randomly to get the optimal solution to a problem. Temperature SA decreases from high to low. The change is expected to get an optimal global solution. Some researchers also have studied preventive maintenance. Shirmohammadi, et al. [5] proposed a non-linear optimization model based on age. It is used to optimize single component preventive maintenance schedules. Moghaddam [6] compared SA with other algorithms such as the Genetic Algorithm (GA) and a Steady State Genetic Algorithm (SSGA). Allaoui and Artiba [7] used a combination simulation model and machine scheduling optimization with more than one objective function. One of the developments of GA is the GA hybrid used by Nguyen, et al. [8]. In actual conditions, optimization using conventional methods does not get convergent results because the objective function is more than one challenge.

Several researchers have researched other metaheuristic algorithms. Azadeh, et al. [9] developed a hybrid metaheuristic algorithm on employee scheduling optimization. The metaheuristic hybrid algorithm also has been used by Pooranian, et al. [10], Allahyari, et al. [11], and Liu and Kozan [12]. Furthermore, Nasir, et al. [13] proposed a spiral adaptive dynamic metaheuristic algorithm. Several researchers have carried out the use of SA in various fields. Vahedi Nouri, et al. [14] used for cases of machines with non-fixed operating times. Wang, et al. [15] applied to the chemical distillation optimization process. Kang and Zhu [16] applied SA to solve the problem of train passenger waiting time. Zhang, et al. [17] used SA to track differences in areas experiencing drought based on time intervals. Jerin Leno, et al. [18] proposed a strategy to increase the convergence of the SA algorithm.

In this article, we use SA for maintenance scheduling. This algorithm was chosen because it was never used in literature before. Annealing is illustrated as a physical process. In the process, the substantial heated until it reaches high temperatures. Furthermore, the solid is slowly allowed to cool. In the process, all particles make themselves slowly reach a low level of energy. The final energy level depends on the temperature and cooling rate. SA is a simulation that starts with a scorching temperature. Next, the simulation will end at a minimum final value. The purpose of this study is to determine the optimal preventive maintenance schedule using SA. The proposed scheduling model is based on cost and reliability weighting match functions. The difference between this research and the previous one weighs and schedules based on the consistency of the algorithm during the treatment period. The treatment period is a concern of the researcher. The schedule formed is recommended for 12 months or more. The schedule was not verified. We need to do Validation for a more extended period. The proposed algorithm uses a match function that matches the company's problems. This study carries out several scenarios of weight reliability and cost.

\section{Methods}

\subsection{Simulated Annealing Algorithm}

Optimization in SA used two objective functions. The function is the total cost and reliability function. According to Moghaddam [6], the form of the objective function is shown in equation (1) and equation (2). 
total cost $=\sum_{i=1}^{N} \sum_{j=1}^{T}\left[F_{i} \cdot \lambda_{i}\left(\left(X_{i, j}^{\prime}\right)^{\beta_{i}}-\left(X_{i, j}\right)^{\beta_{i}}\right)+M_{i} \cdot m_{i, j}+R_{i} \cdot r_{i, j}\right]+\sum_{j=1}^{T}\left[Z\left(1-\prod_{i=1}^{N}\left(1-\left(m_{i, j}+r_{i, j}\right)\right)\right)\right]$

reliability $=\prod_{i=1}^{N} \prod_{j=1}^{T} e^{-\left[\lambda_{i}\left(\left(x_{i, j}^{\prime}\right)^{\beta_{i}}-\left(x_{i, j}\right)^{\beta_{i}}\right)\right]}$

the notation used in both functions is as follows:

$N$ : number of sub-machines

$T$ : a treatment period

$F_{i}$ : sub-machines breakdown cost $i$

$\beta_{i}$ : sub-machines shape parameter $i$

$\lambda_{i}: 1 / \alpha_{i}$, and $\alpha_{i}:$ scale parameter

$M_{i}$ : sub-machines treatment cost $i$

$R_{i}$ : sub-machines replacement cost $i$

$Z$ : downtime fixed cost

$m_{i, j}: 1$ if treatment is carried out and 0 if treatment is not carried out

$r_{i, j}: 1$ if the replacement is carried out and 0 if replacement is not carried out

$X_{i, j}:\left(1-m_{i, j-1}\right)\left(1-r_{i, j-1}\right) X_{i, j-1}^{\prime}+m_{i, j-1}\left(\gamma_{i} . X_{i, j-1}^{\prime}\right)$; and $0 \leq \lambda_{i} \leq 1$.

$X_{i, j}^{\prime}: X_{i, j}+\frac{T}{J} ; J$ is a number of discrete intervals in a period $[0, T]$.

$Z(t)$ : normalization factor

$T(t)$ : solid temperature

$S$ is an initial scheduling solution

The annealing process is described as a stochastic procedure in a physical phenomenon. The solid undergoes many random transitions from different energy levels to the balance point at each temperature level. The energy level is random so that the opportunity value can statistically describe it. If $X$ states the random energy level of solids with the energy level $\mathrm{E}$, then the chance is written $P(X=E)$ (equation (3)).

$P(X=E)=\frac{1}{Z(t)} e^{\left(\frac{-E}{K_{B} T(t)}\right)}$

$Z(t)$ is a normalization factor, $\mathrm{T}(\mathrm{t})$ is the stable temperature, and $\mathrm{K}_{\mathrm{B}}$ is Boltzmann's constant, $1.38064852 \times 10^{-23} \mathrm{~J} / \mathrm{K}$. The distribution of opportunities is called Boltzmann Distribution. Suppose the temperature of $\mathrm{T}(\mathrm{t})$ decreases. In that case, the chance of a balance with a higher energy level has a chance that is not zero. If cooling is rapid, heat balance cannot be achieved at any temperature level, so the solid reaches a meta-stable condition.

In choosing an optimal schedule, researchers used a match function. A match function is a type of objective function that quantifies the optimality of the solution. Matching functions are used for weighting between functions of total costs (total costs) and functions of reliability (reliability) by Moghaddam [6]. Weighting is based on the needs of the company. If the company prefers to issue a higher machine, then the weight of $w 2$ is more considerable than $w 1$ and vice versa. The matching function is described in equation (4). 
Fitness $_{1}=w_{1}\left(\frac{\text { Total } \operatorname{cost}}{\operatorname{Cost}_{\max }}\right)+w_{2}(-$ reliability $)$

Where $w 1$ and $w 2$ is which weight $w 1+w 2=1$. Total Cost is a function of the total cost, with Costmax the maximum cost value of the process simulated annealing. Reliability is a reliability function which is the second objective function. The SA procedure from Kuo, et al. [19] is shown in Algorithm 1.

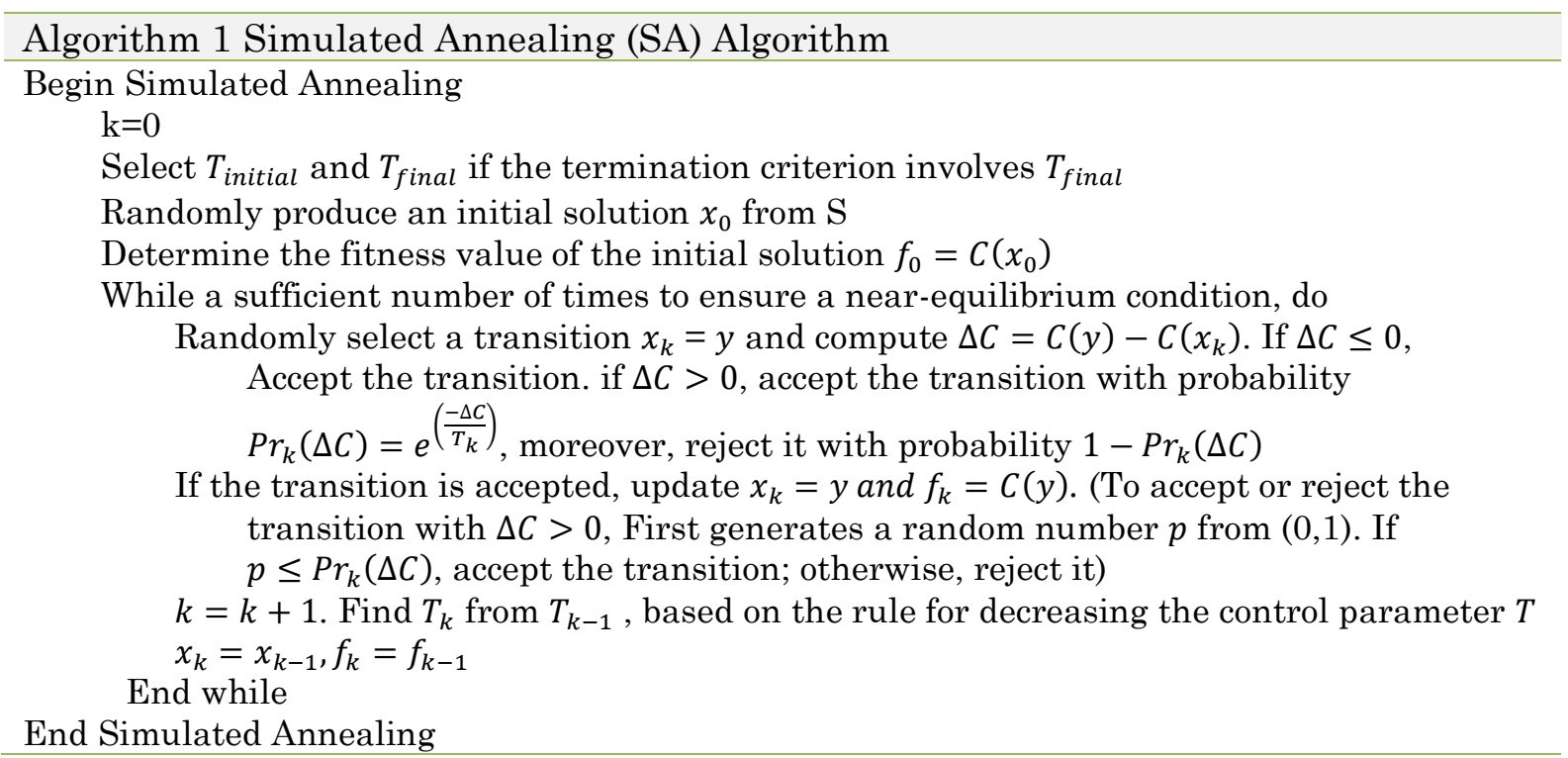

\subsection{Experimental Procedures}

This study used several ASA inputs presented in Table 1. The initial temperature was the initial condition of the iteration. The final temperature was the final value intended from the iteration of the simulated annealing algorithm. At the same time, the iteration rate was $99 \%$, which indicates that the iteration was carried out carefully.

Table 1. SA Variable Input

$\begin{array}{ll}\text { Variable Input } & \text { Score } \\ \text { Number of Sub-machines } & 4 \\ \text { Treatment period } & 6 \\ \text { Initial Temperature } & 10^{6} \\ \text { Final Temperature } & 10^{-6} \\ \text { Geometric Decreasing Rate } & 0,99\end{array}$

This algorithm was implemented to determine preventive maintenance scheduling for HPFQ machines. The machine has four sub-machine as sub-machine Press, Loader, Ejector, and Heating. The analysis was carried out at the time of breakdown. The data were tested for distribution compatibility and estimated parameters. The parameter time of breakdown is one of the inputs in the SA. The distribution comes from data on the time of sub-machine breakdown that has been collected by Giovani [20]. Table 2 describes the distribution of breakdown time for each sub-system along with the estimated parameters. Table 2 shows that sub-machine breakdown time is Weibull distribution and cost. 
Table 2. Time of Sub-system Breakdown Distribution and Costs

\begin{tabular}{|c|c|c|c|c|c|c|}
\hline \multirow[b]{2}{*}{$\begin{array}{l}\text { Sub } \\
\text { machines }\end{array}$} & \multirow[b]{2}{*}{$\begin{array}{l}\text { Breakdown } \\
\text { Distribution }\end{array}$} & \multicolumn{2}{|c|}{ Estimated Parameter } & \multicolumn{3}{|c|}{ Cost (IDR) } \\
\hline & & $\begin{array}{l}\text { alpha (scale } \\
\text { parameter) }\end{array}$ & $\begin{array}{l}\text { beta (shape } \\
\text { parameter) }\end{array}$ & $\begin{array}{l}\text { Breakdown } \\
\text { (Fi) }\end{array}$ & $\begin{array}{l}\text { treatment } \\
\text { (Mi) }\end{array}$ & $\begin{array}{l}\text { Replacement } \\
\text { (Ri) }\end{array}$ \\
\hline Press & & 115.0032 & 1.4694 & $9,744,352.94$ & $33,096.95$ & $2,297,539.26$ \\
\hline Loader & Weibull & 131.4796 & 1.2005 & $7,599,827.10$ & $29,295.04$ & $1,008,442.96$ \\
\hline Ejector & Weibull & 122.0742 & 1.8763 & $7,225,662.70$ & $28,811.67$ & $743,037.95$ \\
\hline Heating & Weibull & 591.6664 & 2.5168 & $15,200,098.11$ & $34,845.00$ & $7,359,973.60$ \\
\hline
\end{tabular}

Fixed cost downtime $\left(Z_{\mathrm{i}}\right)=$ IDR 4,500,000,-

Several experiments were carried out to obtain optimal total costs. Eleven trials were carried out to obtain the Total Cost Based on the Combination Weight of the Match Function. Furthermore, 11 experiments were carried out to obtain the reliability function based on weight matching functions. Each experiment used cost weights (W1) and different reliability (W2). Furthermore, the researcher provides several proposed preventive maintenance scenarios.

\section{Result and Discussions}

The results of several trials can be seen in Fig. 1 and Fig. 2. These present a weighting simulation with various combinations. Fig. 1 shows that the cost weight (W1) is increased and the weight of reliability is lowered (W2). The combination of the two weights results in a total cost that tends to decrease. This result proved research from Moghaddam [6]. Fig. 2 shows a decreasing trend in reliability [6]. The experiment in Fig. 2 also used the same weighting scenario as the experiment in Fig. 1.

The treatment period applied to the multi-subsystem SA case is six months. After that period, the maintenance schedule is changed every time the program starts. The researcher also proposed five scheduling possibilities. The schedule can be seen in Table 3, Table 4, Table 5, Table 6, and Table 7. There are several actions taken based on the proposed schedule. These actions are Replacement (R), Maintainance (M), and no action is needed (-).

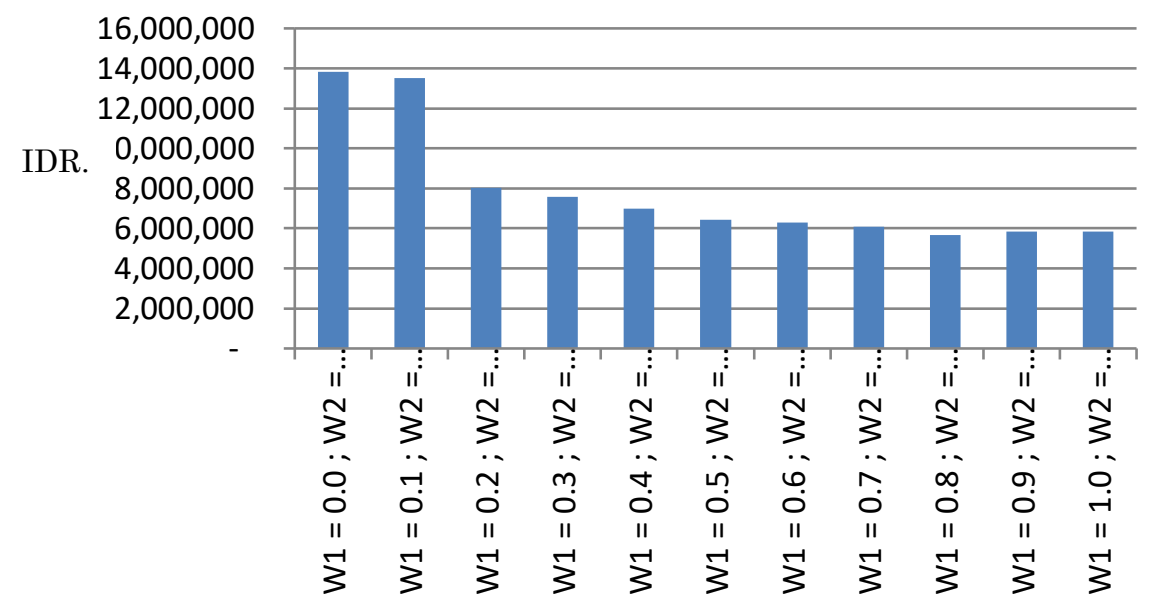

Fig. 1. Total Cost Based on Combination Weight Matching Function 


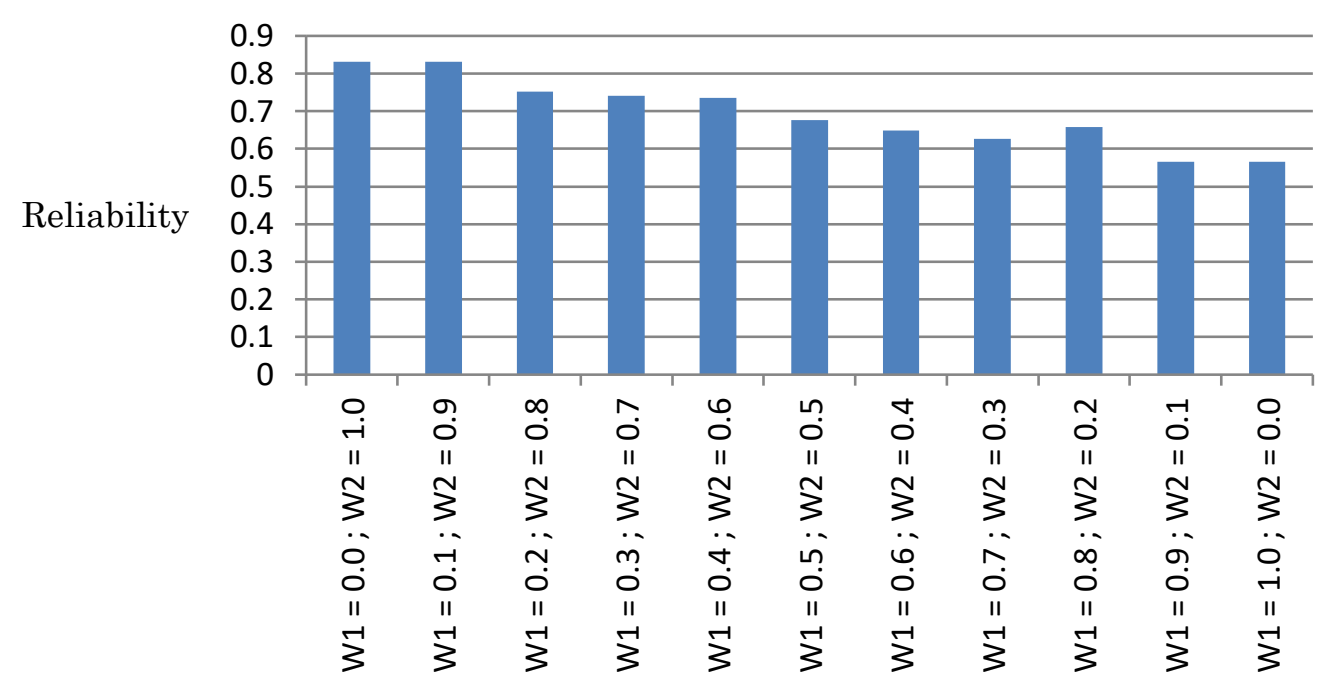

Fig. 2. Reliability based on the combined weight of the match function

Table 3. Preventive Maintenance Schedule Scenario $1(\mathrm{~W} 1=0.0 ; \mathrm{W} 2=1.0)$

\begin{tabular}{llllrll} 
Sub & & \multicolumn{5}{c}{ Month } \\
machines & 1 & 2 & 3 & 4 & 5 & 6 \\
\hline Press & $\mathrm{R}$ & $\mathrm{R}$ & $\mathrm{R}$ & $\mathrm{R}$ & $\mathrm{R}$ & $\mathrm{M}$ \\
Loader & $\mathrm{R}$ & $\mathrm{R}$ & $\mathrm{R}$ & $\mathrm{R}$ & $\mathrm{R}$ & $\mathrm{M}$ \\
Ejector & $\mathrm{R}$ & $\mathrm{R}$ & $\mathrm{R}$ & $\mathrm{R}$ & $\mathrm{R}$ & $\mathrm{M}$ \\
Heating & $\mathrm{R}$ & $\mathrm{R}$ & $\mathrm{R}$ & $\mathrm{R}$ & $\mathrm{R}$ & $\mathrm{M}$ \\
\hline
\end{tabular}

Table 3 shows a preventive maintenance schedule with maximum weighting on reliability $(\mathrm{W} 1=0.0 ; \mathrm{W} 2=1.0)$. The weighting does not consider the cost element in its match function. Using this weighting, the sub-system component must be replaced from the 1 st month to the 5 th month. Whereas in the 6th-month, treatment was taken. The total cost incurred to carry out maintenance using the scheduling is IDR $13,829,600$ with the resulting reliability of $83.07 \%$.

Table 4. Preventive Maintenance Schedule Scenario $2(\mathrm{~W} 1=0.1 ; \mathrm{W} 2=0.9)$

\begin{tabular}{lllllll} 
Sub & \multicolumn{6}{c}{ Month } \\
machines & 1 & 2 & 3 & 4 & 5 & 6 \\
\hline Press & $\mathrm{R}$ & $\mathrm{R}$ & $\mathrm{R}$ & $\mathrm{R}$ & $\mathrm{R}$ & - \\
Loader & $\mathrm{R}$ & $\mathrm{R}$ & $\mathrm{R}$ & $\mathrm{R}$ & $\mathrm{R}$ & - \\
Ejector & $\mathrm{R}$ & $\mathrm{R}$ & $\mathrm{R}$ & $\mathrm{R}$ & $\mathrm{R}$ & - \\
Heating & $\mathrm{R}$ & $\mathrm{R}$ & $\mathrm{R}$ & $\mathrm{R}$ & $\mathrm{R}$ & - \\
\hline
\end{tabular}

Table 4 shows the weighted preventive maintenance schedule $\mathrm{W} 1=0.1 ; \mathrm{W} 2=0.9$. This weighting gives a higher weight to reliability and gives a small weight to the cost of the match function. If using this weighting, the components in the sub-system must be replaced from the 1 st month to the 5th month. While in the 6th month there is no need to take care measures. The total cost for maintenance using the scheduling is IDR 13,517,400 with reliability equal to the first weighting scenario of $83.07 \%$. 
Table 5 shows the preventive maintenance schedule with weighting on the cost component, which is 0.2 and 0.3 . If using this weighting, the component in the sub-system must be replaced in the 2nd and fourth months. Furthermore, sub-systems do not need to take care of actions. The total cost incurred for maintenance using the scheduling ranges from IDR 7,572,400 - IDR 8,038,600 with a reliability of $74.01 \%-75.20 \%$.

Table 5. Preventive Maintenance Schedule Scenario $3(\mathrm{~W} 1=0.2 ; \mathrm{W} 2=0.8)$ and $(\mathrm{W} 1=0.3 ; \mathrm{W} 2=0.7)$

\begin{tabular}{llllcll}
\hline \multirow{2}{*}{$\begin{array}{l}\text { Sub } \\
\text { machines }\end{array}$} & 1 & 2 & 3 & 4 & 5 & 6 \\
\hline Press & - & $\mathrm{R}$ & - & $\mathrm{R}$ & - & - \\
Loader & - & $\mathrm{R}$ & - & $\mathrm{R}$ & - & - \\
Ejector & - & $\mathrm{R}$ & - & $\mathrm{R}$ & - & - \\
Heating & - & $\mathrm{R}$ & - & $\mathrm{R}$ & - & - \\
\hline
\end{tabular}

Table 6 shows the preventive maintenance schedule by weighting the enlarged cost component from 0.4 to 0.8 . If using this weighting, then the component in the sub-system must be replaced in the 3rd month. The total costs incurred for maintenance use the scheduling between IDR 5,653,420 - IDR 6,996,660 with reliability $62.72 \%-73.59 \%$.

Table 6. Preventive Maintenance Schedule Scenario $4(\mathrm{~W} 1=0.4 ; \mathrm{W} 2=0.6)$ and $(\mathrm{W} 1=0.8 ; \mathrm{W} 2=0.2)$

\begin{tabular}{lllllll}
\hline Sub & \multicolumn{7}{c}{ Month } \\
\cline { 2 - 4 } & 1 & 2 & 3 & 4 & 5 & 6 \\
\hline Press & - & - & $\mathrm{R}$ & - & - & - \\
Loader & - & - & $\mathrm{R}$ & - & - & - \\
Ejector & - & - & $\mathrm{R}$ & - & - & - \\
Heating & - & - & $\mathrm{R}$ & - & - & - \\
\hline
\end{tabular}

Table 7. Preventive Maintenance Schedule Scenario $5(\mathrm{~W} 1=0.9 ; \mathrm{W} 2=0.1)$

\begin{tabular}{lllllll} 
Sub & \multicolumn{7}{c}{ month } \\
machines & 1 & 2 & 3 & 4 & 5 & 6 \\
\hline Press & - & - & - & - & - & - \\
Loader & - & - & - & - & - & - \\
Ejector & - & - & - & - & - & - \\
Heating & - & - & - & - & - & - \\
\hline
\end{tabular}

At weighting $\mathrm{W} 1=0.9$ and $\mathrm{W} 2=0.1$, based on the schedule formed in Table 7 . The researchers found no need to take action for over six months because using scenario 5 . The scenario requires submissions with minimum reliability. Although the costs incurred are maximum, but do not affect the minimum target reliability. So that SA does not recommend taking care of actions. 


\section{Conclusion}

This study concludes that the SA method is helpful in preventive maintenance determinations. In some experiments, the combination of the weight of the match function resulted in a total cost and reliability that tended to decrease. Based on the analysis results using a weighting match function, there are four HPFQ machine maintenance preventive schedule scenarios. Each scenario has cost consequences and the value of the reliability/reliability of the machine. Further research can examine how long-term preventive maintenance scheduling uses SA to produce a consistent schedule. The researcher can use simulations of the breakdown time distribution parameters to see the behavior of the scheduling.

\section{References}

[1] E. Pan, G. Wang, L. Xi, L. Chen, and X. Han, "Single-machine group scheduling problem considering learning, forgetting effects and preventive maintenance," International Journal of Production Research, vol. 52, pp. 5690-5704, 2014. https://doi.org/10.1080/00207543.2014.904967.

[2] T. Chen, J. Li, P. Jin, and G. Cai, "Reusable rocket engine preventive maintenance scheduling using genetic algorithm," Reliability Engineering \& System Safety, vol. 114, pp. 52-60, 2013. https://doi.org/10.1016/j.ress.2012.12.020.

[3] N. Ayoobian and M. Mohsendokht, "Multi-objective optimization of maintenance programs in nuclear power plants using Genetic Algorithm and Sensitivity Index decision making," Annals of Nuclear Energy, vol. 88, pp. 95-99, 2016. https://doi.org/10.1016/j.anucene.2015.10.033.

[4] F. Moinian, H. Sabouhi, J. Hushmand, A. Hallaj, H. Khaledi, and M. Mohammadpour, "Gas turbine preventive maintenance optimization using genetic algorithm," International Journal of System Assurance Engineering and Management, vol. 8, pp. 594-601, 2017. https://doi.org/10.1007/s13198-017-0627-3.

[5] A. H. Shirmohammadi, Z. G. Zhang, and E. Love, "A Computational Model for Determining the Optimal Preventive Maintenance Policy With Random Breakdowns and Imperfect Repairs," IEEE Transactions on Reliability, vol. 56, pp. 332-339, 2007. https://doi.org/10.1109/TR.2007.896747.

[6] K. S. Moghaddam, "Preventive maintenance and replacement scheduling: models and algorithms," Doctoral Dissertation, Industrial Engineering, University of Louisville, 2010. https://doi.org/10.18297/etd/994.

[7] H. Allaoui and A. Artiba, "Integrating simulation and optimization to schedule a hybrid flow shop with maintenance constraints," Computers \& Industrial Engineering, vol. 47, pp. 431-450, 2004. https://doi.org/10.1016/j.cie.2004.09.002.

[8] P. K. Nguyen, T. G. Crainic, and M. Toulouse, "A hybrid generational genetic algorithm for the periodic vehicle routing problem with time windows," Journal of Heuristics, vol. 20, pp. 383-416, 2014. https://doi.org/10.1007/s10732-014-9244-3.

[9] A. Azadeh, M. H. Farahani, H. Eivazy, S. Nazari-Shirkouhi, and G. Asadipour, "A hybrid meta-heuristic algorithm for optimization of crew scheduling," Applied Soft Computing, vol. 13, pp. 158-164, 2013. https://doi.org/10.1016/j.asoc.2012.08.012.

[10] Z. Pooranian, M. Shojafar, R. Tavoli, M. Singhal, and A. Abraham, "Hybrid metaheuristic algorithm for job scheduling on computational grids," Informatica, vol. 37, 2013. www.informatica.si/index.php/informatica/article/viewFile/445/449.

[11] S. Allahyari, M. Salari, and D. Vigo, "A hybrid metaheuristic algorithm for the multi-depot covering tour vehicle routing problem," European Journal of 
Operational Research, vol. 242, pp. $\quad 756-768, \quad 2015$. https://doi.org/10.1016/j.ejor.2014.10.048.

[12] S. Q. Liu and E. Kozan, "A hybrid metaheuristic algorithm to optimise a real-world robotic cell," Computers \& Operations Research, vol. 84, pp. 188-194, 2017. https://doi.org/10.1016/j.cor.2016.09.011.

[13] A. N. K. Nasir, R. M. T. Raja Ismail, and M. O. Tokhi, "Adaptive spiral dynamics metaheuristic algorithm for global optimisation with application to modelling of a flexible system," Applied Mathematical Modelling, vol. 40, pp. 5442-5461, 2016. https://doi.org/10.1016/j.apm.2016.01.002.

[14] B. Vahedi Nouri, P. Fattahi, and R. Ramezanian, "Hybrid firefly-simulated annealing algorithm for the flow shop problem with learning effects and flexible maintenance activities," International Journal of Production Research, vol. 51, pp. 3501-3515, 2013. https://doi.org/10.1080/00207543.2012.750771.

[15] Y. Wang, G. Bu, Y. Wang, T. Zhao, Z. Zhang, and Z. Zhu, "Application of a simulated annealing algorithm to design and optimize a pressure-swing distillation process," Computers \& Chemical Engineering, vol. 95, pp. 97-107, 2016. https://doi.org/10.1016/j.compchemeng.2016.09.014.

[16] L. Kang and X. Zhu, "A simulated annealing algorithm for first train transfer problem in urban railway networks," Applied Mathematical Modelling, vol. 40, pp. 419-435, 2016. https://doi.org/10.1016/j.apm.2015.05.008.

[17] H. Zhang, N. Li, W. Zhang, and X. Pei, "Experiments to automatically monitor drought variation using simulated annealing algorithm," Natural Hazards, vol. 84, pp. 175-184, 2016. https://doi.org/10.1007/s11069-016-2414-x.

[18] I. Jerin Leno, S. Saravana Sankar, and S. G. Ponnambalam, "An elitist strategy genetic algorithm using simulated annealing algorithm as local search for facility layout design," The International Journal of Advanced Manufacturing Technology, vol. 84, pp. 787-799, 2016. https://doi.org/10.1007/s00170-013-5519-3.

[19] W. Kuo, V. R. Prasad, F. A. Tillman, and C.-L. Hwang, Optimal reliability design: fundamentals and applications: Cambridge university press, 2001. http://sutlib2.sut.ac.th/sut_contents/H113121.pdf.

[20] G. Giovani, "Optimization of preventive maintenance scheduling using genetic Algorithm," Bachelor Program, Department of Statistics, Universitas Padjadjaran, Bandung, 2018. 